Original Research Paper

\title{
Determination of Thermal Comfort for Social Impact Assessment: Case Study in Kota Damansara, Selangor, Malaysia
}

\author{
${ }^{1}$ Nor Hanisah Mohd Hashim, ${ }^{2}$ Kok Weng Tan and ${ }^{3}$ Yvonne Ling \\ ${ }^{1}$ Universiti Teknologi MARA, Selangor, Malaysia \\ ${ }^{2}$ Universiti Tunku Abdul Rahman, Perak, Malaysia \\ ${ }^{3}$ SEGi University, Selangor, Malaysia
}

Article history

Received: 27-04-2016

Revised: 20-06-2016

Accepted: 08-11-2016

Corresponding Author:

Nor Hanisah Mohd Hashim

Universiti Teknologi MARA,

Selangor, Malaysia

Email: norhanisah@salam.uitm.edu.my

\begin{abstract}
This study determined the thermal comfort of outdoor recreational park in Kota Damansara, Malaysia. Predicted Mean Vote (PMV) index, Predicted Percentage of Dissatisfied (PPD) and Thermal Sensation Vote (TSV) were applied in order to determine thermal comfort in the study area. Comparison and establishment of relationship were done between PMV and Predicted Percentage of Dissatisfied (PPD) to demographic factors and affecting factors among visitors of public parks in Kota Damansara. Based on the research analysis, the thermal comfort ranges in urban recreational park of Kota Damansara was within the comfort zone and satisfactory to its users. The comfort level of both public parks by using PMV and TSV was +1.5 and 0 while PPD was $56.70 \%$. The result of this study showed that comfort zone of respondents shifted towards the right of TSV curve. Compact human settlement in the city exacerbated the development of housing to meet the demand, thus affected the amount of green areas available in study area. The results from the research could be useful for landscape's architect, urban planner and engineers to create a sustainable development in Malaysia or all over the world.
\end{abstract}

Keywords: Environmental Impact Assessment, Urban Planning, Thermal Comfort

\section{Introduction}

Population increment in the world obviously causes more emerging technologies to cope with human living standard. Urban is a place where human have vast jobs opportunities contributing to high productivity, luxurious lifestyle and massive network of transportation, unfortunately, accompanied by urban heat island. Urban heat island greatly affecting urban in a way that the heat trapped in building blocks of the city will lead to warmer temperature compared to rural areas outside the city. Compact human settlement in the city allows more room for development of housing to meet the demand that in turn impacted amount of green areas available. Options for human comfort in warm climate and limited space in urban areas include green belt policy (NE, 2010) or assessment of thermal comfort.

Thermal comfort can be defined as condition of mind that expresses satisfaction with the thermal environment
(ANSI/ASHRAE Standard 55, 2010). When an occupant of a building generates heat and is allowed to dissipate into surrounding environment, thermal comfort of the individual is maintained. If the environment conditions is depriving for the individual, health effects such as heat stroke and heat exhaustion may occur (Curriero et al., 2002). Thermal sensation is defined as a conscious experience resulting from exposure to a group of variables making up the thermal environment (ASHRAE, 1981). Thus, standard of thermal comfort is needed for assessing human comfort. American Society of Heating, Refrigerating and Air-Conditioning Engineers (ASHRAE) established Standard 55 which titled 'Thermal Environmental Conditions for Human Occupancy' in year 1992. The main purpose of the standard is to specify the combinations of indoor thermal environmental factors and personal factors that will produce thermal environmental conditions acceptable to $80 \%$ or more of the occupants within a space 
(ANSI/ASHRAE Standard 55, 2010). It includes four environmental factors and two personal factors namely humidity, temperature, thermal radiation, air velocity activity and clothing. Development of this standard is useful for landscape's architect, urban planner and engineers to promote sustainable development dealing with global warming. Apart from developing energy efficiency building such as green building, many deaths occurred during winter time can also be prevented with proper housing conditions.

\section{Outdoor Thermal Comfort}

Solar radiation from outdoor environment clearly gives an effect on thermal comfort of a subject. Hodder and Parsons (2007) studied the relationship between thermal comfort and exposure of solar radiation. The experiment conducted in an environmental chamber with monitored environmental conditions such as air temperature, mean radiant temperature, relative humidity and air velocity. Three designs of experiment was conducted to determine effect of radiation intensity, effect of spectral content of radiation and effect of glazing type respectively. By applying International Organization of Standardization (ISO) thermal sensation scale, a linear relationship was established between level of stimulated solar radiation and thermal sensation rating. Apart from ratings, supporting evidence proving solar radiation for determination of thermal comfort is the mean skin temperature measurements.

Multiple logistics regression can also relate the environmental parameters and personal parameters along with preferences votes (Oliveira and Andrade, 2007). Bioclimatic comfort is assessed in a leisure area and results reflect possibility to identify preferences of subject in outdoor environment conditions, even with the influential personal characteristics such as gender and age. Other than that, an indoor model was applied to outdoor conditions but with careful steps due to the large gap of indoor and outdoor environments conditions. Subjects performing moderate to vigorous physical activities had been modeled using Comfort Formula (COMFA) outdoor thermal comfort model (Kenny et al., 2009). Outdoor thermal comfort model is based on heat and moisture flux of one's body's energy with its environment. However, it's a disadvantage when the model act to over- or underestimated the heat and moisture exchange as much as $6 \%$ of total cases. Sensitivity analysis is recommended to determine changes of each COMFA model inputs that will affect its outputs. Inputs can be air temperature, Controlled Room Temperature (CRT), metabolic activity or relative humidity.

Another popular index that had been utilized to measure outdoor comfort range is Physiological Equivalent Temperature (PET). Along with daily climatic data collected for the past 11 years, amount of rainfall and days count with rain can dramatically affect PET values, thus affecting thermal comfort (Kenny et al., 2009). This is due to the reason that climate in the study area are very prone to heat-related ailments. PET values were categorized into grades according to level of physiological stress. Chen and $\mathrm{Ng}$ (2012) summarized the application of models and indicators that are widely used and some discussion on evaluating behavioral aspects of outdoor thermal comfort. Outdoor thermal comfort assessment can be categorized into two types which are steady-state assessment and nonsteady-state assessment methods.

Steady-state assessment linked human thermal sensation with microclimatic conditions. PMV indices developed by Fanger (1982) are widely utilized on measuring thermal response based on seven-point scale which is $+3=$ hot, $+2=$ warm, $+1=$ slightly warm, $0=$ neutral, $-1=$ slightly cool, $-2=$ cool, $-3=$ cold. PMV indices often combined with PPD. Few other steady-state models are PET (Mayer and Hoppe, 1987), which is based on Munich Energy-balance Model for Individual (MEMI), Index of Thermal Stress (ITS) (Givoni et al., 2003), COMFA outdoor thermal comfort model (Kenny et al., 2009) and Outdoor Standard Effective Temperature (OUTSET) (De Dear and Brager, 2002).

For non-steady-state model such as Pierce Two Node Model, it could possibly portray dynamic and detailed study however there are no internationally accepted non steady-state indices (Hoppe, 2002). Skin temperature that is needed as an input appear to be a drawback of this assessment method as it is not feasible and practical in outdoor cases. Nikolopoulou et al. (2004) extensively studied thermal comfort of outdoor spaces using field surveys and environmental monitoring data. Thermal comfort responses are determined by relationship of subjective thermal responses with microclimatic parameters and building models. Data of microclimatic parameters to build a model can be acquired from local meteorological stations. Actual Sensation Vote (ASV) has been employed and the results are correlated with microclimatic parameters. There are weak correlations between these two ASV and microclimatic parameters simply indicate that one parameter is insufficient for thermal comfort assessment. Besides that, ASV is also compared to PMV and only 59\% of PMV falls within comfort proves that solely physiological approach is unsatisfactory to identify outdoor thermal comfort conditions. Trial to develop model using multiple linear and stepwise regression found to be significant for all microclimatic parameters except for Relative Humidity (RH). Adding correction factors to model developed could be useful for urban designers to fully utilize outdoor open spaces in urban.

Apart from using various models for assessing thermal comfort, calibration is often needed to accurately reflect the results based on field studies conducted. Monteiro and Alucci (2006) had provided calibration for widely used 
outdoor thermal comfort assessment as much as 20 predictive models which some are from Givoni et al. (2003; Nikolopoulou et al., 2004; Jendritzky, 1991). Calibration of the models would be used to assess outdoor thermal comfort in Grande Sao Paulo, Brazil. Methodologies involved two approaches which were field research and simulation and calibration of those models. Microclimatic variables measurements and questionnaires were conducted in summer and winter. All the models summed up to 32 types of indexes and are computationally processed whereby the results were compared to conducted field researches that will provide calibration value for the models. To establish the calibration values, three criteria were developed as below:

- 1st criterion: Correlation of model parameter and results of thermal sensation responses

- 2nd criterion: Correlation of index and results of thermal sensation responses

- 3rd criterion: Percentage of correct predictions

Range limits for all indexes were changed to obtain maximum percentage of correct predictions and maximum correlation between model parameters or indexes with results of thermal sensation responses. In conclusion, models with high possibility of predicting thermal sensation responses are considered by having good correlation of $1 \mathrm{st}$ criterion due to high potential to accurately predict thermal sensations after the calibration of these models.

Many researches had focused on quantitative approach in discussing outdoor thermal comfort conditions. In a research done by Nikolopoulou and Steemers (2003), psychological adaptation was implemented into her research linked to thermal sensation. Naturalness, expectations, experience on short and long term, time of exposure, perceived control are psychological adaptations issue where its relative weight need to be addressed and understanding of its interconnections. Adaptation of humans towards outdoor thermal comfort was suggested when the Actual Percentage of Dissatisfied (APD) were very different from theoretical PPD. The term naturalness is describe as an environment without artificiality whereby it is the main concern of this research because this factor is not influenced by any other factors however as an integral part in psychologically influencing user's perception on thermal comfort endurance to wide changes of environment. Parameters which are taken into consideration are experience and perceived control. Users experiences in a city of natural and built environments whether indoor or outdoor could affect their thermal sensation. Some environments of shady areas, breeze exposure and access to sun can be controlled and this also will drive user's perceptions on thermal comfort. Nikolopoulou and Steemers (2003) emphasizes that psychological adaptation need to be taken into account on urban planning along with basis physical model to increase usage of outdoor space.

Gomez-Apeitia et al. (2011) had also researched on comparison of outdoor and indoor thermal comfort temperatures. The method they employed was different with most of the research by imparting Averages for Thermal Sensation Intervals (ATSI). As it named, intervals from data obtained will be used to calculate mean and standard deviation and subsequently draw regression line. From the results of his research, he found that human may achieve higher tolerance of indoor temperatures than outdoor in winter. This is due to the need to conceal body temperature when indoor temperature is hot and human body is acclimatize to the environment which the comfort temperature range is larger. In contrast, during summer, the comfort ranges decreases. Respondents' houses made of concretes and cement absorb and retain heat well making indoor temperature higher than outside. In turn, the respondents had adjusted to their expectations.

Kantor and Unger (2010) studied the outdoor thermal comfort conditions in an urban park in inner city of Szeged (South-East Hungary). In commons, the methodology involves calculation of PET derived from in situ meteorological data. Another special feature included in this research was application of Geographical Information System (ArcView). Human observations method clearly gives information on personal characteristics and the pattern of movement in the urban park. With the aid of ArcView GIS 3.3, data collected are processed and area usage maps were created. Field study was only conductedin spring and autumn for the period of study of 2 years (2008-2009). Thermal comfort conditions are estimated using data available from nearest meteorological station. Additional subjective information was gathered through social surveys and unobstructed observations. Mapping of study area was also done to accurately illustrate buildings and trees along with surface covers. Weather conditions was also observed and classified into overcast, partly cloudy and clear. Data digitization in ArcView allows convenient data interpretation such as queries on any respondents and grouping them into any combinations. The research showed that human physical adaptation make them extend the time spent on outdoors and reduced clothing values. The number of respondent increases when the environment conditions are considered thermally stressed and it is explained by research of Nikolopoulou and Steemers (2003).

Monteiro and Alucci (2009) addressed the presence of vegetation impacting outdoor thermal comfort in urban spaces in Sao Paulo, Brazil. Two major comparison of study area were chosen whereby the first area was fully shaded by trees and another area shaded by processed materials. Measurements and 
questionnaires survey was also set up in three targeted conditions namely under open sky, shaded by trees and under a processed cover. Significant differences of thermal sensations can be observed in summer compared to winter which the result was quite similar. Under shaded trees, thermal sensation conditions are more likely to be neutral than open sky. Apart from that, respondents' thermal sensations are cooler under shaded trees than under processed materials. The differences in thermal conditions could be insignificant in morning but it gets more significant when the day reach afternoon.

Zambrano et al. (2006) addresses evaluations of outdoor thermal comfort of Rio de Janeiro. As in practice, Fanger's model that are widely used considering environmental and individual parameters (PMV and PPD). An acceptable thermal condition as suggested by ISO 7730 is to have less than $10 \%$ of PPD. Thermal comfort analysis was done by using ASV and prediction of comfort had been done through PMV and PPD. At last, two results from the study will be compared. 40 questionnaires are done in 4 different points in a square which was located under shades, sunny area, partial shade area and fully shaded with vegetation respectively. Results of point 2 (sunny area) happens to have unsatisfactory percentage although overall results showed high level of satisfaction $(77 \%)$. However, prediction of comfort using PMV and PPD found that there are higher PPD ranges from 31-100\% whilst in observed results, there are only high satisfaction percentage. They expecting the results would be contrasted due to the fact that respondents had already adapted to heat. In conclusion, dissatisfaction of respondents arose because of several factors such as presence of solar radiation, surface temperature of materials and presence of ground cover of vegetation which are aligned with obtained environmental parameters measurements. Methods employed by PMV and PPD reflect the need of changing the urban space. Despite of the dissatisfaction of respondents in the study area, the comfort conditions of the space are considerable due to the climatic conditions of Rio de Janeiro. In months of cold climate, the sunny areas can be a dynamic space.

\section{Malaysia's Geography and Climate}

Malaysia is situated along the equatorial and located in southeast of Asia. The climate is tropical with annual southwest (April to October) and northeast (October to February) monsoon wind. The terrain ranges from coastal plains to rising hills and mountains. Average annual population growth rate in 2010 is reported as much as $1.6 \%$ which makes up 28.3 million people living in Malaysia (DSM, 2010). Selangor appeared to be the most populous state by reporting 5.46 million people and urban growth rate had increased to $71.0 \%$ since 2000. High level of urbanization can be observed in Federal Territory of Kuala Lumpur and Putrajaya. Selangor has about $91.4 \%$ urbanization level. This indicates that Selangor is experiencing rapid growth of its economy where the population centralized in this state. The first 6 months of 2012 had attracted foreign investment on projects amounted up to RM 3.4 billion.

The challenge of the urbanization is to meet people's need. Low cost housing project that had been proposed becomes a conflict with raw material prices such as cement. Current slow development of housing causes houses price to hike when it fail to meet population demand. Only $87.2 \%$ of house ownership reported in Selangor compared to other states which had 93.4 and 93.3\% for Kelantan and Kedah respectively (PGM, 2012). Alternative to the issue raised is the proposal of energy-efficient buildings by Real Estate and Housing Developers' Association Malaysia (REHDA). Total 26\% of global greenhouse emissions come from energy supply needed to generate electricity while land use, land use change and forestry contribute to $17 \%$.

\section{Microclimatic Parameters (February)}

During the month of research (February 2013), Malaysia is at the edge of northeast monsoon season which will usually end in March. Monthly rainfall is above average and raining often occurs in the evening. Approximately 9-22 days of rainfall occurred in peninsular states which include Selangor. Lowland areas recorded temperature ranges from $25.6-28.7^{\circ} \mathrm{C}$ (MMD, 2013).

In this research, air temperature, relative humidity, wind speed and solar radiation were measured. For both public parks, survey conducted in morning starts at 7-10 am and 5-7 pm in afternoon. However, calculation of Mean Radiant Temperature (MRT) is needed to calculate PMV. It can be measured using globe thermometer and become an input for MRT calculation. To avoid tedious calculation of MRT, data from secondary source was used which is shown in Table 1.

Table 1. Meteorological parameters

\begin{tabular}{|c|c|c|c|c|}
\hline Parameters & Minimum & Maximum & Mean \pm standard error & Standard deviation \\
\hline Ambient Temparature, ${ }^{\circ} \mathrm{C}$ & 24.4 & 32.2 & $28.5 \pm 0.1$ & 1.8 \\
\hline Relative Humidity, \% & 52.0 & 96.0 & $70.8 \pm 0.6$ & 9.9 \\
\hline Air Velocity, $\mathrm{ms}^{-1}$ & 0.0 & 3.1 & $1.3 \pm 0.0$ & 0.8 \\
\hline Physiological Equivalent Temperature, ${ }^{\circ} \mathrm{C}$ & 20.8 & 39.7 & $26.9 \pm 0.2$ & 3.3 \\
\hline Mean Radiant Temperature, ${ }^{\circ} \mathrm{C}$ & 24.5 & 50.5 & $33.3 \pm 0.3$ & 4.9 \\
\hline
\end{tabular}

Source: (Nasir et al., 2012) 


\section{Background of Study Area}

Kota Damansara Township was chosen as a study area. It is located in the sub district of Sungai Buloh in Petaling Jaya, Selangor Malaysia. It is a 4,000-acre $\left(16 \mathrm{~km}^{2}\right)$ developing township with upcoming Sungai Buloh-Kajang Line. Recreational parks in Kota Damansara were chosen as the study area to assess outdoor thermal comfort. Recreational park extensively serves its user originate from surrounding or even those who came further than the nearby area. Two large parks were chosen for the assessment which was Lake Garden at section 6 (coordinate$3.157,101.579$ ) and RimbaRiang Recreational Park at section 9 (coordinate- 3.180,101.583) (Fig. 1). These two parks were frequently visited in morning and afternoon. The Lake Garden was surrounded by semidetached houses and the lake was extended to another zone of housing area. The available exercises facilities and benches are limited but the trees are considerably dense to shade the path walk. There are a number of entrances into the park from 2 different housing areas. Parking lot is available in the main entrance near to where the survey will be conducted. RimbaRiang Recreational Park has more promising facilities such as public toilets, sitting area with roof, children playground and exercises equipment. There are numerous trees but all the trees had not fully grown up where the height is about 2-3 meters tall. The surface covers of the entrance are concrete with small bushes and flowers around the sitting area where the survey is conducted.

\section{Methodology}

\section{Questionnaire Survey}

A total of 30 questionnaire surveys had been conducted in 2 different places with 15 surveys each. The questionnaire was designed based on three sections. Section A consists of demographic information of respondents such as age, gender, occupation, religion, race, nationality and income. Section B refers to visitor's house and visiting frequency, while Section $C$ refers to the environmental parameters such as soft-scape and hardscape of recreational parks. The time frame and frequency visiting at the park was also noted. The seven point ASHRAE thermal sensation scale are:

- $\quad+3=$ Hot

- $\quad+2=$ Warm

- $\quad+1=$ Slightly Warm

- $0=$ Neutral

- $\quad-1=$ Slightly Cool

- $-2=$ Cool

\section{- $\quad-3=$ Cold}

The respondents were also asked to rate their current thermal sensation using the ASHRAE thermal sensation scale for determination of TSV. Clothing type and activity can be observed and noted. Hence, the range of value clothing would be calculated to be compared with PMV. The survey questions include how they scale the affecting factors of perceiving thermal comfort such as lighting intensity, wind velocity, air temperature and presence of hardscapes. The scale used was semantic scales with 5 intervals (best, good, average, bad and worst).

\section{Respondents Information}

Table 2 showed the respondents information for this study. Majority of respondents fall into age ranges from $21-30$ as much as $43.30 \%$ followed by $20 \%$ of respondents within range of age $31-40$. The percentage for respondent's age ranges from 10-20 and $61-70$ are same which was $10.00 \%$ or 3 person count. For the age range of 41-50, respondents participated was $16.70 \%$. Respondent's gender for female and male is 15 for both. Out of 30 respondents, Malay appear to be the majority with $66.70 \%$ followed by Chinese, Indian and others with percentages of $23.30,6.70$ and $3.30 \%$ respectively. Thus, religion was expected to portray similar trend as ethnic composition. $66.70 \%$ of respondents belong to Islam while $6.70 \%$ of respondents belong to Christian. The other two religions were Buddha and Hindu with percentage of 16.70 and $10.00 \%$ respectively.

Only Malaysian was involved in the survey with sum of 30 local people. Occupations of respondents can be categorized into seven division named professionals, non-professionals, retired, housewives, students and self-employed. $43.30 \%$ of respondents belong to professionals which require special skill in their job. Students and nonprofessional comprise $16.70 \%$ of the total respondents. Retiree and housewives have the same percentage which were $10.00 \%$ and the least respondents involve in the survey with $3.30 \%$ is selfemployed. The income ranges can be divided into 7 categories where the largest percentages of respondents is as much as $43.30 \%$ falls into income range $<\mathrm{RM} 2,000$ while the least percentage of respondents is from income range of $<\mathrm{RM} 11,000$ and $<$ RM 20,000 with only $3.30 \%$. About $23.30 \%$ of the total respondents have income range $<\mathrm{RM} 5,000$ followed by income range $<$ RM 8,000 with $16.70 \%$. Degree qualification seems to be significant in the survey having $36.70 \%$ or 11 respondents. Then, it is followed by $23.30 \%$ for secondary level, $20.00 \%$ for diploma, $13.30 \%$ for SPM level and $6.70 \%$ for STPM level. 


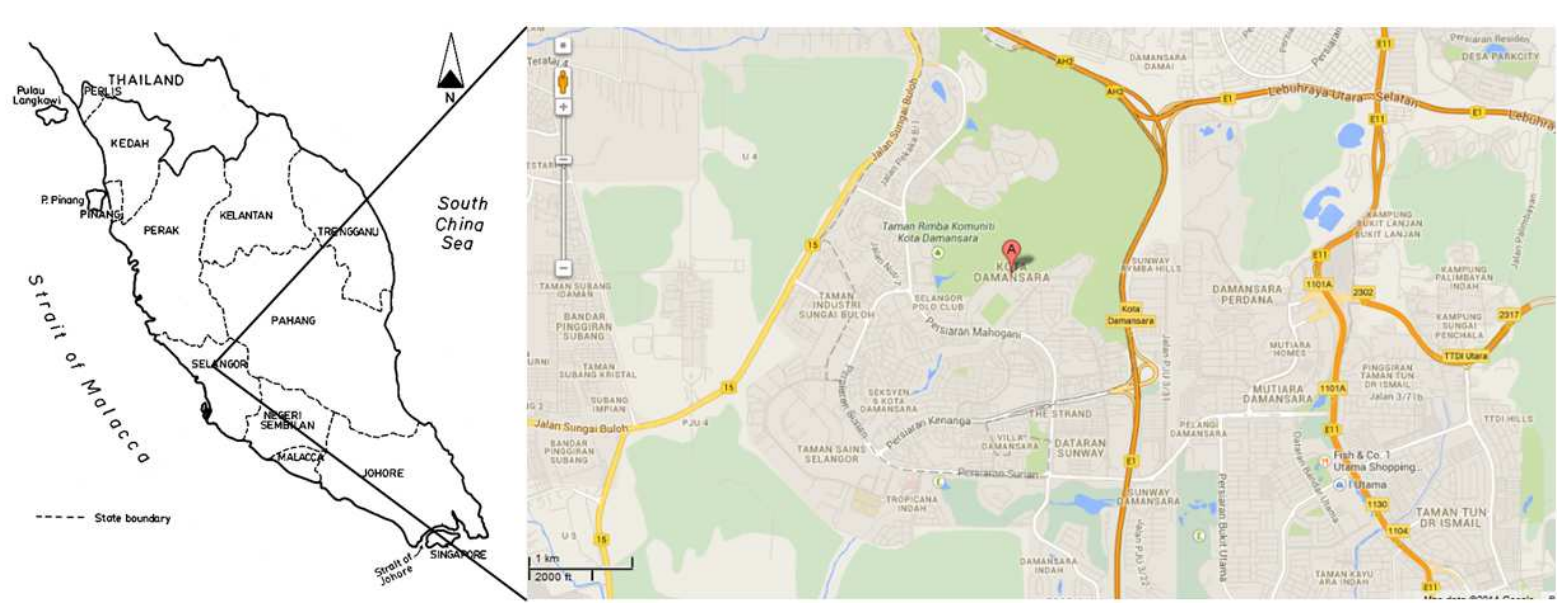

Fig. 1. The location of Kota Damansara, Selangor in Peninsular Malaysia (Source: Edited from FAO, 2014; Google Maps, 2014)

Table 2. Respondents information in study area

\begin{tabular}{|c|c|c|c|}
\hline & Range/Category & Frequency & Percent \\
\hline \multicolumn{4}{|l|}{ Age } \\
\hline & $10-20$ & 3 & 10.0 \\
\hline & $21-30$ & 13 & 43.3 \\
\hline & $31-40$ & 6 & 20.0 \\
\hline & $41-50$ & 5 & 16.7 \\
\hline & $61-70$ & 3 & 10.0 \\
\hline \multicolumn{4}{|c|}{ Gender } \\
\hline & Male & 15 & 50.0 \\
\hline & Female & 15 & 50.0 \\
\hline \multicolumn{4}{|c|}{ Ethnicity } \\
\hline & Malay & 20 & 66.7 \\
\hline & Indian & 2 & 6.7 \\
\hline & Chinese & 7 & 23.3 \\
\hline & Others & 1 & 3.3 \\
\hline \multicolumn{4}{|c|}{ Religion } \\
\hline & Islam & 20 & 66.7 \\
\hline & Christian & 2 & 6.7 \\
\hline & Buddhist & 5 & 16.7 \\
\hline & Hindu & 3 & 10.0 \\
\hline \multicolumn{4}{|c|}{ Nationality } \\
\hline \multicolumn{4}{|c|}{ Occupation } \\
\hline & Professional & 13 & 43.3 \\
\hline & Non-Professional & 5 & 16.7 \\
\hline & Retired & 3 & 10.0 \\
\hline & Housewife & 3 & 10.0 \\
\hline & Student & 5 & 16.7 \\
\hline & Self-Employed & 1 & 3.3 \\
\hline \multicolumn{4}{|c|}{ Income } \\
\hline & $<\operatorname{Rm} 2,000$ & 13 & 43.3 \\
\hline & $<\operatorname{Rm} 5,000$ & 7 & 23.3 \\
\hline & $<\operatorname{Rm~} 8,000$ & 5 & 16.7 \\
\hline & $<\mathrm{Rm} 11,000$ & 1 & 3.3 \\
\hline & $<\operatorname{Rm} 20,000$ & 1 & 3.3 \\
\hline & Others & 3 & 10.0 \\
\hline \multicolumn{4}{|c|}{ Qualifications } \\
\hline & Secondary & 7 & 23.3 \\
\hline & Spm & 4 & 13.3 \\
\hline & Stpm & 2 & 6.7 \\
\hline & Diploma & 6 & 20.0 \\
\hline & Degree & 11 & 36.7 \\
\hline Total & & 30 & 100.0 \\
\hline
\end{tabular}




\section{Predicted Mean Vote and Predicted Percentage} Dissatisfied Theory

According to ANSI/ASHRAE Standard 55 (2010) prediction of thermal comfort by using steady-state energy balance will determine PMV index. The equation is developed by Fanger (1970) as below:

$$
P M W=[0.303 \exp (-0.036 M)+0.028] L
$$

Where:

$M=$ Rate of metabolic heat production, $\mathrm{W} / \mathrm{m}^{2}$

$L=$ Thermal load on the body, defined as the difference between internal heat production and heat loss to the actual environment for a person hypothetically

Value of M can be estimated from activity level of a person by using Table 3 . The equation for $L$ is the differences between right and left side equation as follows:

$$
\begin{aligned}
& M-W=3.96 \times 10^{-8} f_{c l}\left[\left(t_{c l}+273\right)^{4}-\left(t_{r}+273\right)^{4}\right] \\
& +f_{c l} h_{c}\left(t_{c l}-t_{a}\right)+3.05\left[5.73-0.007(M-W)-p_{a}\right] \\
& +0.42[(M-W)-58.15] \\
& +0.0173 M\left(5.87-p_{a}\right) \\
& +0.0014 M\left(34-t_{a}\right)
\end{aligned}
$$

Where:

$M=$ Rate of metabolic heat production, $\mathrm{W} / \mathrm{m}^{2}$

$W=$ Rate of mechanical work accomplished, $\mathrm{W} / \mathrm{m}^{2}$

$f_{c l}=$ Clothing area factor $\mathrm{Acl} / \mathrm{AD}$, dimensionless

$t_{c l}=$ Clothing temperature, ${ }^{\circ} \mathrm{C}$

$t_{r}=$ Mean radiant temperature, ${ }^{\circ} \mathrm{C}$

$h_{c}=$ Convective heat transfer coefficient, $\mathrm{W} / \mathrm{m}^{2} /{ }^{\circ} \mathrm{C}$

$t_{a}=$ Air temperature, ${ }^{\circ} \mathrm{C}$

$p_{a}=$ Partial water vapour pressure in air, $k P a$

As a part of the energy balance equation, the clothing temperature, $t_{c l}$, was calculated by iteration as:

$$
\begin{aligned}
& t c l=35.7-0.028(M-W) \\
& -R_{c l}\left\{39.6 \times 10^{-9} f_{c l}\left[\left(t_{c l}+273\right)^{4}-\left(t_{r}+273\right)^{4}\right]\right. \\
& \left.+f_{c l} h_{c}\left(t_{c l}-t_{a}\right)\right\}
\end{aligned}
$$

To find clothing area factor $\mathrm{Acl} / \mathrm{AD}$, dimensionless, $f_{c l}$, the following equation is used:

$$
\begin{array}{r}
f_{c l}=1.0+0.2 I_{c l} \text { when, } I_{c l}<0.5 \mathrm{clo} \\
\text { or, }=1.05+0.1 I_{c l} \text { when, } I_{c l}>0.5 \mathrm{clo}
\end{array}
$$

Table 3. Typical metabolic heat generation for various activities

\begin{tabular}{lll}
\hline & $\mathrm{W} / \mathrm{m}^{2}$ & met $^{\mathrm{a}}$ \\
\hline Resting & & \\
Sleeping & 40 & 0.7 \\
Reclining & 45 & 0.8 \\
Seated, quiet & 60 & 1.0 \\
Standing, relaxed & 70 & 1.2 \\
Walking (on level surface) & & \\
$3.2 \mathrm{~km} / \mathrm{h}(0.9 \mathrm{~m} / \mathrm{s})$ & 115 & 2.0 \\
$4.3 \mathrm{~km} / \mathrm{h}(1.2 \mathrm{~m} / \mathrm{s})$ & 150 & 2.6 \\
$6.4 \mathrm{~km} / \mathrm{h}(1.8 \mathrm{~m} / \mathrm{s})$ & 220 & 3.8 \\
Office Activities & & \\
Reading, seated & 55 & 1.0 \\
Writing & 60 & 1.0 \\
Typing & 65 & 1.1 \\
Filing, seated & 70 & 1.2 \\
Filing, standing & 80 & 1.4 \\
Walking about & 100 & 1.7 \\
Lifting/packing & 120 & 2.1 \\
Driving/flying & & \\
Car & $60-115$ & $1.0-2.0$ \\
Aircraft, routine & 70 & 1.2 \\
Aircraft, instrument landing & 105 & 1.8 \\
Aircraft, combat & 140 & 2.4 \\
Heavy vehicle & 185 & 3.2 \\
\hline Source (ASHRAE, & &
\end{tabular}

Source: (ASHRAE, 2001)

Heat transfer took place in each individual was either free convection or forced convection. Therefore, convective heat transfer coefficient, $h_{c}$, will be determined as follows:

$$
\begin{aligned}
h_{c} & =2.38\left(t_{c l}-t_{a}\right)^{0.25} \quad 2.38\left(t_{c l}-t_{a}\right)^{0.25}>12.1\left(V^{0.5}\right) \\
o r, & =12.1\left(V^{0.5}\right) \quad 2.38\left(t_{c l}-t_{a}\right)^{0.25}<12.1\left(V^{0.5}\right)
\end{aligned}
$$

According to Harvey and Huang (2007) the partial water vapour pressure in air, $p_{a}$, is the product of saturated vapour pressure and relative humidity given by:

$$
p_{a}=p_{s a t} x t_{a} x R H
$$

Where:

$p_{\text {sat }}=$ Saturation vapour pressure, $\mathrm{kPa}$

$R H=$ Relative humidity, \%

To find $p_{\text {sat }}$, Antoine's formula is utilized:

$p_{\text {sat }}=0.1333 \exp \left(18.6686-4030.183 / t_{a}+235\right)$

After PMV index were estimated, another method employed to relate PMV was estimation of PPD. Fanger (1982) established the relationship as:

$P P D=100-95 \exp \left[-\left(0.03353 P M V^{4}+0.2179 P M V^{2}\right)\right]$ 
The graph for PMV-PPD model will reflect the percentage of dissatisfied of $5 \%$ at $\mathrm{PMV}=0$

\section{Data Analysis}

In order to calculate PMV with the data available, repetitive calculation for 30 data were collected. Visual Basic for Application (VBA) in Excel is appropriate for the PMV determination. By recording macro in VBA and stored in module, specific effect will take in workbook according to the formula that had been inserted into macro. Macro acts as storage for formula and a template for input of environment parameters and personal parameters. PMV can be calculated by inserting the input into its respective column. Statistical Package for Social Sciences (SPSS Version 20) will be used to analyze the data collected. This software was suitable for researcher to gather and analyze the data digitally. Trends, charts and formula can effectively illustrate data outcome in a few clicks which was very convenient for the user. Data collected were used to establish PMV and PPD. Hypothesis was derived from the results along with other analyzed data. Demographic data was compared to PMV using Chi square test of independence to observe its significance. Results of affecting factors are also compared to PMV. The comparison generate links or relationship of affecting factors and demographic with PMV or PPD.

\section{Reliability of Dependent Variables}

Cronbach's alpha coefficient as an indicator for reliability of dependent variable was tested using SPSS. When the result of test had internal consistency with the alpha value above 0.70 it signify that the scale used acceptable. For this research, the dependent variables were tested for reliability and showed value above 0.70 and is deemed acceptable.

There is limitation for ranges of input in PMV model for metabolic rates, clothing, air temperature, mean radiant temperature and air velocity (Havenith et al., 2002). Recommended and ranges used in this study is tabulated in Table 4. The value used in this study had exceeded the recommended ranges and the results depicts out of range for PMV from -3 to +5 .

\section{Results of Predicted Mean Vote and Percentage of Dissatisfied of Public Park}

Microclimatic parameters were measured in morning and afternoon in recreationalpark, Kota Damansara. The average for environment parameters measurement is shown in Table 5. Secondary data is used to substitute unavailability of measurement of environment parameters in recreational park for PMV calculation. As for recreationalpark, although there are measurements made, mean radiant temperature requires globe temperature and thus, secondary data is also used.

\section{Predicted Mean Vote of Recreational Parks}

Thermal Sensation Vote (TSV) is the expression of respondents regarding their comfort level during survey according to ASHRAE 7 point scale. $80 \%$ of respondents believed that from -2 to +2 are their comfort range (Fig. 2). The wide range of comfort zone could be due to wider tolerance towards understanding of lack of control towards variation of outdoor environment parameters. The PMV estimation by using steady-state energy balance model involved input such as air temperature, relative humidity, wind speed, mean radiant temperature, clothing value and activity level.

Table 4.Comparison of PMV range with actual study

\begin{tabular}{lll}
\hline Parameters & Recommended ranges & Range used in this study \\
\hline Metabolic rates (met) & $0.8-4.0$ & $1.0-3.8$ \\
Clothing (clo) & $0.0-2.0$ & $0.29-0.72$ \\
Air temperature $\left({ }^{\circ} \mathrm{C}\right)$ & $10.0-30.0$ & $24.4-32.2$ \\
Mean radiant temperature $\left({ }^{\circ} \mathrm{C}\right)$ & $10.0-40.0$ & $24.5-50.5$ \\
Air velocity $(\mathrm{m} / \mathrm{s})$ & $0.0-1.0$ & $0.0-0.31$ \\
\hline
\end{tabular}

Table 5. Microclimatic measurement of recreational parks

Recreational parks

\begin{tabular}{|c|c|c|c|c|c|c|c|c|}
\hline \multirow{3}{*}{$\frac{\text { Date }}{16 / 2 / 2013}$} & \multicolumn{8}{|c|}{ Morning/Afternoon } \\
\hline & \multicolumn{2}{|c|}{ Air temperature $\left({ }^{\circ} \mathrm{C}\right)$} & \multicolumn{2}{|c|}{ Relative humidity (\%) } & \multicolumn{2}{|c|}{ Wind speed $(\mathrm{m} / \mathrm{s})$} & \multicolumn{2}{|c|}{ Solar radiation (Lux) } \\
\hline & 27.8 & 30.0 & 76.2 & 60.8 & 0.0 & $* 3.1$ & 164.0 & 500.0 \\
\hline $17 / 2 / 2013$ & 28.6 & 29.8 & 70.7 & 63.5 & 0.0 & $* 3.1$ & 164.0 & 486.0 \\
\hline $23 / 2 / 2013$ & 27.4 & 29.5 & 71.9 & 62.0 & 0.0 & $* 3.1$ & 55.0 & 924.0 \\
\hline $24 / 2 / 2013$ & 28.2 & 29.4 & 67.9 & 72.3 & 0.0 & $* 3.1$ & 150.0 & 1969.0 \\
\hline Average & 28.0 & 29.7 & 71.7 & 64.7 & 0.0 & $* 3.1$ & 133.0 & 970.0 \\
\hline Standard deviation & 0.5 & 0.3 & 3.5 & 5.2 & 0.0 & 0.0 & 52.6 & 696.5 \\
\hline
\end{tabular}

*secondary data from (Nasir et al., 2012) 
Table 6. Chi-square test for Predicted Mean Vote (PMV) with dependent variables

\begin{tabular}{lccc}
\hline Dependent variables & Value & df & Asymp. Sig. (2-sided) \\
\hline Section B & & & 0.351 \\
Type of dwelling & 75.986 & 72 & 0.591 \\
Length of staying & 33.432 & 36 & 0.291 \\
Comfort status & 78.095 & 72 & 0.449 \\
Length of time staying in park & 18.095 & 18 & $* 0.029$ \\
Frequency of visiting park & 96.500 & 72 & 0.203 \\
Section C & & & $* 0.048$ \\
Air quality & 62.381 & 54 & 0.443 \\
Temperature & 72.364 & 54 & 0.089 \\
Lighting & 73.068 & 72 & 0.272 \\
Wind & 68.500 & 54 & $* 0.033$ \\
Landscape setting & 78.808 & 72 & 0.440 \\
User-friendly & 74.615 & 54 & 0.720 \\
Odour & 54.917 & 54 & 0.955 \\
Accessibilities & 47.542 & 54 & 72 \\
Tree's density & 52.976 & 72 & \\
\hline
\end{tabular}

* denotes value that is lesser than $\alpha=0.05$; * denotes value that is lesser than $\alpha=0.05$ and strongly significant

Table 7. The choice of clothing worn by respondents in public parks of Kota Damansara

Garment descriptions

Men's brief, t-shirt, ankle length athletic socks, walking shorts

Clo value

Men's brief, short sleeved, knit sport shirt, ankle length athletic socks, walking shorts

0.29

Men's brief, short sleeved, knit sport shirt, slippers, walking shorts

Men's brief, t-shirt, ankle length athletic socks, sweatpants bra, panties, T-shirt,

Sweatpants, ankle length athletic socks

Men's brief, t-shirt, slippers, sweatpants

Men's brief, short sleeved, knit sport shirt, sweatpants, ankle length athletic socks 0.53

Bra, panties, straight trousers (thick), long sleeve sweaters (thin), sandals

0.53

Bra, panties, ankle length athletic socks, sweatpants, long sleeve sweaters (thin)

0.61

Bra, panties, ankle-length athletic socks, sweatpants, long sleeved (thin)

Bra, panties, ankle length athletic socks, long sleeved flannel shirt, sweatpants

0.70

Bra, panties, ankle length athletic socks, sweatpants, long sleeve sweaters (thick)

0.72

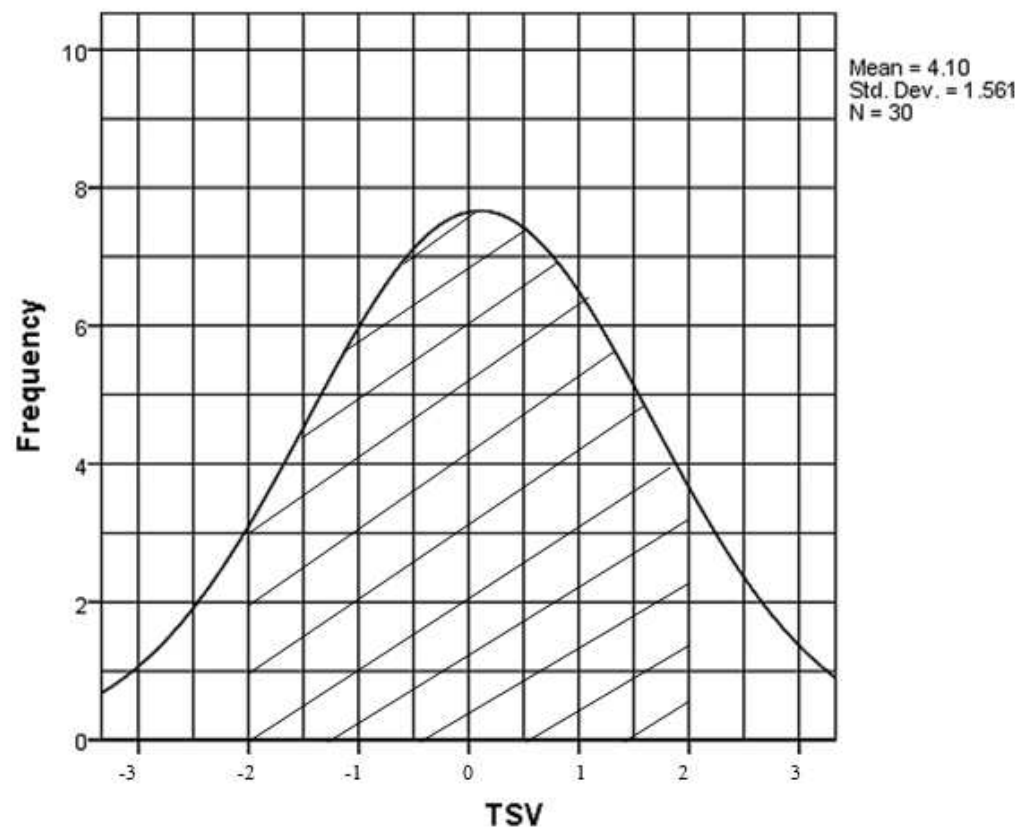

Fig. 2. Thermal Sensation Vote (TSV) of recreational parks in Kota Damansara 
The results of calculation for PMV inrecreationalpark showed $80 \%$ of respondents were in comfort zone at -0.06 to +2.69 . The distribution is slightly deviating from Thermal Sensation Vote (TSV). The deviation from TSV is expected to occur in tropical climate due to physiological acclimatization of people to the temperature in hot and humid climate $\chi^{2}(54)=72.364, n$ $=30, p=0.048$. This can be explained by (Kantor and Unger, 2010) where human may tolerate outdoor environment which made them extends the time of visiting the park and adjusts the clothing worn.

In this study, the respondents may choose to visit the park often instead of extending the time due to satisfaction of thermal sensation in the park $\chi^{2}(72)=$ 96.500, $n=30, p=0.029$. The Chi-square test of independence for Predicted Mean Vote (PMV) with dependent variables was shown on Table 6. Majority of respondents wear clothing value of approximately 0.47 clo. Clothing worn in outdoor recreationalpark ranges from 0.29 to 0.72 clo was affecting the PMV curve to deviate from TSV (Table 7). With the choice of clothing worn by majority of respondents, PMV depicts that they will feel slightly warm to warm which would probably place them in discomfort zone.

TSV results had shown otherwise where majority of respondents are in their comfort zone by expressing their comfort level as neutral. The user-friendly features in the park is associated with PMV in the way that respondents may psychologically feel that park are more user defined $\chi^{2}(54)=74.615, n=30, p=0.033$.

Predicted Mean Vote and Predicted Percentage of Dissatisfied of Recreational Park in Kota Damansara

PMV values were plotted against PPD value from calculation using Excel (Fig. 3). From the trend observed, the shaded region represents dissatisfied percentage of respondents. The results is not consistent with PMV which theoretically when PMV value approaches -0.06, PPD would shows only $5.10 \%$ of dissatisfaction. Comparing to PMV value earlier, +1.5 is the optimum value (slightly warm to warm) where majority of respondents are comfortable. They are satisfied with the warm conditions surrounding the recreational park. However, the PPD value at +1.6 had shown that $56.70 \%$ respondents are dissatisfied with their comfort level.

\section{Demographic Information with the Crosstab Analysis}

Chi-square method was employed to test on the association between variables in contingency tables (Investopedia US, 2013). The alpha was determined to be 0.05 generally in social science. This method requires one independent variable and one dependent variable. The significant association will be determined if the answer for Pearson Chi-square have lower value than alpha $(\alpha=0.05)$.

\section{Age Factor}

Age factor as an independent variable were tested using chi-square test for independence against dependent variables for type of dwelling, length of inhabiting the house, current comfort status, length of time staying in the park and frequency of visiting the park along with next section of questionnaire which consists of air quality, temperature, lighting, wind, landscape setting, user-friendly, odor, accessibilities and tree's density. The results were tabulated as in Table 8 . The test failed to indicate a significant difference, for all of the dependent variables except for tree's density in public park, $\chi^{2}(16)$ $=28.137, n=30, p=0.030$ (an alpha level of 0.05 was adopted for this and all subsequent statistical tests). The association could be due to different sensitivity levels of age groups towards tree's density.

Table 8. Chi-square test of independence for age with dependent variables

\begin{tabular}{llll}
\hline Dependent variables & Value & df & Asymp. Sig. (2-sided) \\
\hline Section B & & & 0.446 \\
Type of dwelling & 16.096 & 16 & 0.125 \\
Length of staying & 12.634 & 8 & 0.195 \\
Comfort status & 20.596 & 16 & 0.294 \\
Length of time staying in park & 4.933 & 4 & 0.383 \\
Frequency of visiting park & 17.046 & 16 & 0.451 \\
Section C & & & 0.543 \\
Air quality & 11.929 & 12 & 0.124 \\
Temperature & 10.835 & 12 & 0.163 \\
Lighting & 22.617 & 16 & 0.368 \\
Wind & 16.646 & 12 & 0.356 \\
Landscape setting & 17.271 & 16 & 0.245 \\
User-friendly & 13.179 & 12 & 0.090 \\
Odor & 14.929 & 12 & $* 0.030$ \\
Accessibilities & 18.942 & 12 & 16 \\
Tree's density & 28.137 & 16 & \\
t & &
\end{tabular}

* denotes value that is lesser than $\alpha=0.05 ;{ }^{* *}$ denotes value that is lesser than $\alpha=0.05$ and strongly significant. 
Table 9. Chi-square test of independence for gender with dependent variables

\begin{tabular}{lccc}
\hline Dependent variables & Value & df & Asymp. Sig. (2-sided) \\
\hline Section B & & & 0.671 \\
Type of dwelling & 2.353 & 4 & 0.766 \\
Length of staying & 0.533 & 2 & 0.098 \\
Comfort status & 7.825 & 4 & 0.232 \\
Length of time staying in park & 1.429 & 1 & 0.509 \\
Frequency of visiting park & 3.300 & 4 & 0.767 \\
Section C & & & 0.153 \\
Air quality & 1.143 & 3 & 0.543 \\
Temperature & 5.273 & 3 & 0.494 \\
Lighting & 3.091 & 4 & 0.510 \\
Wind & 2.400 & 3 & 0.245 \\
Landscape setting & 3.292 & 4 & 0.416 \\
User-friendly & 4.154 & 3 & 0.972 \\
Odour & 2.844 & 3 & 0.777 \\
Accessibilities & 0.234 & 3 & 4 \\
Tree's density & 1.778 & 4 & \\
\hline
\end{tabular}

* denotes value that is lesser than $\alpha=0.05 ; * *$ denotes value that is lesser than $\alpha=0.05$ and strongly significant

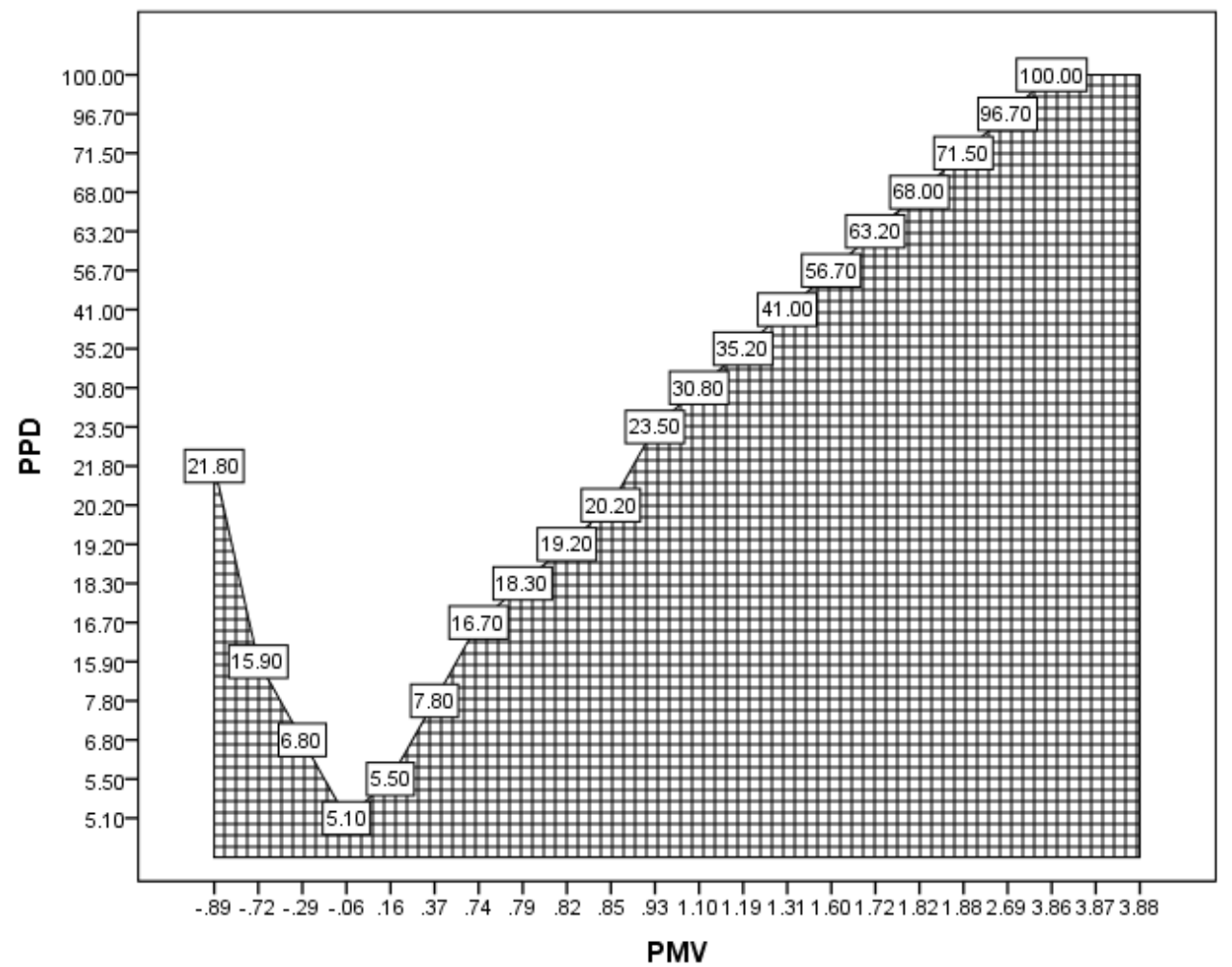

Fig. 3. The Predicted Percentage of Dissatisfied (PPD) for visitors of Recreational Parks in Kota Damansara

\section{Gender Factor}

There are no significant association for recreational park between gender and type of dwelling, length of staying, comfort status, length of time staying in the park and frequency of visiting park as none of the reported asymp. sig. is less than $\alpha=0.05$ (Table 9). The similar result was shown for Section $\mathrm{C}$ which includes association of gender with environment parameters such as air quality, temperature, lighting, wind, landscape settings, odor, accessibilities and tree's density.

\section{Ethnicity Factor}

Ethnicity was tested for its association for the same dependent variables. The result was tabulated in Table 10. There are no significant association between ethnicity and type of dwelling, length of staying, comfort status and frequency to visit recreational park as none of 
the reported asymp. sig. is less than $\alpha=0.05$. However, length of staying showed a significant difference with ethnicity $\chi^{2}(6)=13.342, n=30, p=0.038$. The culture of spending time in park with fishing activities and relaxing with friends and family of certain ethnicity could be a possible reason of relating to time spent in the park. The other dependent variables for section $\mathrm{C}$ are also insignificant.

\section{Religion Factor}

Religion was tested for its association for the same dependent variables. The result was tabulated in Table 11. There are no significant association between religion and type of dwelling, length of staying, comfort status and length of time staying in the park as none of the reported asymp. sig. is less than $\alpha=0.05$. Frequency of visiting park have strong relation to religion in this case $\chi^{2}$
$(12)=28.625, n=30, p=0.004$. Since the park was located near to mosque, it was possible to say that majority of visitors in the park is Muslim. There are also other dependent variables showed same significance difference such as accessibilities $\chi^{2}(9)=17.995, n=30, p=0.03$ and tree's density $\chi^{2}(12)=21.440, n=30, p=0.044$.

\section{Occupation Factor}

Occupations were tested for chi-square of independent to observe its significance of differences with other dependent variables (Table 12). The only dependent variable that passed the chi-square test is lighting for recreational park. It showed significant difference when associated with occupations $\chi^{2}(20)=$ $32.012, n=30, p=0.043$. The reason behind this association could be different demand on artificial lighting in the park due to different exposure.

Table 10. Chi-Square test of independence for ethnicity with dependent variables

\begin{tabular}{lrll}
\hline Dependent variables & Value & df & Asymp. Sig. (2-sided) \\
\hline Section B & & & 0.117 \\
Type of dwelling & 17.948 & 12 & $* 0.038$ \\
Length of staying & 13.342 & 6 & 0.435 \\
Comfort status & 12.133 & 12 & 0.600 \\
Length of time staying in park & 1.871 & 3 & 0.070 \\
Frequency of visiting park & 19.843 & 12 & 0.894 \\
Section C & & & 0.566 \\
Air quality & 4.254 & 9 & 0.393 \\
Temperature & 7.691 & 9 & 0.820 \\
Lighting & 12.672 & 12 & 0.960 \\
Wind & 5.164 & 9 & 0.330 \\
Landscape setting & 4.935 & 12 & 0.561 \\
User-friendly & 10.264 & 9 & 0.099 \\
Odour & 7.737 & 9 & 0.622 \\
Accessibilities & 14.714 & 9 & 12 \\
Tree's density & 9.934 & 9 & \\
\hline
\end{tabular}

* denotes value that is lesser than $\alpha=0.05$; **denotes value that is lesser than $\alpha=0.05$ and strongly significant

Table 11. Chi-Square Test of Independence for Religion with Dependent Variables

\begin{tabular}{|c|c|c|c|}
\hline Dependent variables & Value & $\mathrm{df}$ & Asymp. Sig. (2-sided) \\
\hline \multicolumn{4}{|l|}{ Section B } \\
\hline Type of dwelling & 16.584 & 12 & 0.166 \\
\hline Length of staying & 9.795 & 6 & 0.134 \\
\hline Comfort status & 12.845 & 12 & 0.380 \\
\hline Length of time staying in park & 1.349 & 3 & 0.717 \\
\hline Frequency of visiting park & 28.625 & 12 & $* * 0.004$ \\
\hline \multicolumn{4}{|l|}{ Section C } \\
\hline Air quality & 3.776 & 9 & 0.926 \\
\hline Temperature & 9.473 & 9 & 0.395 \\
\hline Lighting & 13.409 & 12 & 0.340 \\
\hline Wind & 2.817 & 9 & 0.971 \\
\hline Landscape setting & 5.269 & 12 & 0.948 \\
\hline User-friendly & 8.718 & 9 & 0.464 \\
\hline Odor & 6.294 & 9 & 0.710 \\
\hline Accessibilities & 17.995 & 9 & $* 0.035$ \\
\hline Tree's density & 21.440 & 12 & $* 0.044$ \\
\hline
\end{tabular}

* denotes value that is lesser than $\alpha=0.05 ; *$ denotes value that is lesser than $\alpha=0.05$ and strongly significant 
Table 12. Chi-Square Test of Independence for Occupation with Dependent Variables

\begin{tabular}{|c|c|c|c|}
\hline Dependent variables & Value & $\mathrm{df}$ & Asymp. Sig. (2-sided) \\
\hline \multicolumn{4}{|l|}{ Section B } \\
\hline Type of dwelling & 22.023 & 20 & 0.339 \\
\hline Length of staying & 7.644 & 10 & 0.664 \\
\hline Comfort status & 22.389 & 20 & 0.320 \\
\hline Length of time staying in park & 4.115 & 5 & 0.533 \\
\hline Frequency of visiting park & 23.777 & 20 & 0.252 \\
\hline \multicolumn{4}{|l|}{ Section $\mathrm{C}$} \\
\hline Air quality & 17.239 & 15 & 0.305 \\
\hline Temperature & 8.818 & 15 & 0.887 \\
\hline Lighting & 32.012 & 20 & $* 0.043$ \\
\hline Wind & 10.328 & 15 & 0.799 \\
\hline Landscape setting & 14.776 & 20 & 0.789 \\
\hline User-friendly & 6.213 & 15 & 0.976 \\
\hline Odor & 9.202 & 15 & 0.867 \\
\hline Accessibilities & 17.421 & 15 & 0.294 \\
\hline Tree's density & 15.463 & 20 & 0.749 \\
\hline
\end{tabular}

* denotes value that is lesser than $\alpha=0.05 ;{ }^{*}$ denotes value that is lesser than $\alpha=0.05$ and strongly significant

Table 13. Chi-square test of independence for income with dependent variables

\begin{tabular}{|c|c|c|c|}
\hline Dependent variables & Value & df & Asymp. Sig. (2-sided) \\
\hline \multicolumn{4}{|l|}{ Section B } \\
\hline Type of dwelling & 20.479 & 20 & 0.428 \\
\hline Length of staying & 12.360 & 10 & 0.262 \\
\hline Comfort status & 15.358 & 20 & 0.756 \\
\hline Length of time staying in park & 7.017 & 5 & 0.219 \\
\hline Frequency of visiting park & 20.570 & 20 & 0.423 \\
\hline \multicolumn{4}{|l|}{ Section C } \\
\hline Air quality & 10.239 & 15 & 0.804 \\
\hline Temperature & 33.503 & 15 & $* * 0.004$ \\
\hline Lighting & 14.835 & 20 & 0.786 \\
\hline Wind & 14.249 & 15 & 0.507 \\
\hline Landscape setting & 15.762 & 20 & 0.731 \\
\hline User-friendly & 11.883 & 15 & 0.688 \\
\hline Odour & 18.632 & 15 & 0.231 \\
\hline Accessibilities & 14.190 & 15 & 0.511 \\
\hline Tree's density & 18.375 & 20 & 0.563 \\
\hline
\end{tabular}

* denotes value that is lesser than $\alpha=0.05$; **denotes value that is lesser than $\alpha=0.05$ and strongly significant

Table 14. Chi-square test of independence for qualifications with dependent variables

\begin{tabular}{|c|c|c|c|}
\hline Dependent variables & Value & df & Asymp. Sig. (2-sided) \\
\hline \multicolumn{4}{|l|}{ Section B } \\
\hline Type of dwelling & 18.393 & 16 & 0.301 \\
\hline Length of staying & 6.266 & 8 & 0.617 \\
\hline Comfort status & 14.980 & 16 & 0.526 \\
\hline Length of time staying in park & 5.608 & 4 & 0.230 \\
\hline Frequency of visiting park & 20.985 & 16 & 0.179 \\
\hline \multicolumn{4}{|l|}{ Section C } \\
\hline Air quality & 11.767 & 12 & 0.465 \\
\hline Temperature & 6.292 & 12 & 0.901 \\
\hline Lighting & 21.836 & 16 & 0.149 \\
\hline Wind & 10.594 & 12 & 0.564 \\
\hline Landscape setting & 16.425 & 16 & 0.424 \\
\hline User-friendly & 22.101 & 12 & $* 0.036$ \\
\hline Odor & 11.253 & 12 & 0.507 \\
\hline Accessibilities & 12.276 & 12 & 0.424 \\
\hline Tree's density & 9.225 & 16 & 0.904 \\
\hline
\end{tabular}

* denotes value that is lesser than $\alpha=0.05 ;{ }^{* *}$ denotes value that is lesser than $\alpha=0.05$ and strongly significant 


\section{Household Income Factor}

Household income as an independent variable was analysed for chi square test of independence and the results had shown in Table 13. Strong association between lighting and income can be observed $\chi^{2}(15)=$ $33.503, n=30, p=0.004$. This result is consistent with occupation therefore it confirms the differences in demand of each range of income.

\section{Qualifications Factor}

The relationship of qualifications with other dependent variables was tested. The result was depicted in Table 14. User-friendly seems to be related to qualifications in public park $\chi^{2}(12)=22.101, n=30, p=$ 0.036 . There are no other dependent variables that are associated with qualifications.

\section{Conclusion}

The thermal comfort ranges in urban recreational park of Kota Damansara is within the comfort zone and satisfactory to its users. The comfort level of both recreational parks by using PMV and TSV is +1.5 and 0 while PPD is $56.70 \%$. This study showed that comfort zone of respondents shifted towards the right of TSV curve. As stated by Fanger (1982), PMV-PPD model will reflect the percentage of dissatisfied of 5\% at $\mathrm{PMV}=0$. Hence, for this research, PMV at -0.06 (nearest to 0 ) showed $5.10 \%$ of PPD. The outcome for this study could be different from European countries which experiences climate differences compare to tropical climate in Malaysia. A better physiological adaptation was developed due to exposure of hot and humid tropical climate.

Significant association can be found between PMV with frequency of visiting park, air temperature and userfriendly function. Other association that were also prominent in this research were age with tree's density, ethnicity with length of staying, religion with frequency of visiting the park, accessibilities and tree's density, occupation with lighting, income with temperature, qualifications with user-friendly. Further research was encouraged to accurately predict thermal sensation of local environments along with psychological factors and other possible affecting factors. Establishment of precise thermal comfort studies could aid in developing towards greener development to meet population demand and better lifestyle or reduced occupational risks.

\section{Acknowledgment}

The authors express their gratitude to Kota Damansara local communities. Special thanks to Faculty of Engineering and Built Environment, SEGi University for financial and administration support.

\section{Author's Contributions}

Nor Hanisah Mohd Hashim: Participated in all field investigation and data analysis; contributed to the manuscript writing.

Kok Weng Tan: Data analysis and contributed to the manuscript writing.

Yvonne Ling: Participated in all field investigation and data analysis.

\section{Ethics}

It is declared that there are no ethical issues that may arise in the present study.

\section{References}

ANSI/ASHRAE Standard 55, 2010. Thermal environment conditions for human occupancy. ASHRAE. Atlanta, Georgia, US.

ASHRAE, 1981. Standard 62-Ventilation for acceptable indoor air quality. ASHRAE. Atlanta, Georgia, US.

ASHRAE, 2001. ASHRAE Handbook: Fundamentals. American Society of Heating, Refrigerating and AirConditioning Engineers.

Chen, L. and E. Ng, 2012. Outdoor thermal comfort and outdoor activities: A review of research in the past decade. Cities, 29: 118-128. DOI: $10.1016 /$ j.cities.2011.08.006

Curriero, F.C., K.S. Heiner, J.M. Samet, S.L. Zeger and L. Strug et al., 2002. Temperature and mortality in 11 cities of the Eastern United States. Am. J. Epidemiol., 155: 80-87. DOI: 10.1093/aje/155.1.80

De Dear, R.J. and G.S. Brager, 2002. Thermal comfort in naturally ventilated buildings: revisions to ASHRAE Standard 55. Energy Build., 34: 549-561. DOI: $10.1016 / \mathrm{S} 0378-7788(02) 00005-1$

DSM, 2010. Population and housing census Malaysia. Department of Statistics Malaysia, Putrajaya.

Fanger, P.O., 1970. Thermal Comfort: Analysis and Applications in Environmental Engineering. 1st Edn., McGraw- Hill, New York, ISBN-10: 8757103410, pp: 244.

Fanger, P.O., 1982. Thermal comfort. Robert E. Krieger Publishing, Malabar, FL.

FAO, 2014. Peninsular Malaysia map. Food and Agriculture Organization.

Givoni, B., M. Noguchi, H. Saaroni, O. Pochter and Y. Yaacov et al., 2003. Outdoor comfort research issues. Energy Build., 35: 77-86. DOI: $10.1016 / \mathrm{S} 0378-7788(02) 00082-8$

Gomez-Apeitia, G., G. Bojorqez, E. Gonzalez-Cruz, R. Garcia-Cueto and P. Ruiz-Torres et al., 2011. Outdoor and indoor thermal comfort temperatures comparison in warm dry climates. Architecture and Sustainable Development, Proceedings of PLEA. 
Google Maps, 2014. Kota Damansara Malaysia.

Harvey, A.H. and P.H. Huang, 2007. First-principles calculation of the air-water second virial coefficient, Int. J. Thermophys., 28: 556-565.

Havenith, G., I. Holmer and K. Parsons, 2002. Personal factors in thermal comfort assessment: Clothing properties and metabolic heat production. Energy Build., 6: 581-591. DOI: $10.1016 / \mathrm{S} 0378-7788(02) 00008-7$

Hodder, S.G. and K. Parsons, 2007. The effects of solar radiation on thermal comfort. Int. J. Biometeorol., 51: 233-50. DOI: 10.1007/s00484-006-0050-y

Hoppe, P., 2002. Different aspects of assessing indoor and outdoor thermal comfort. Energy Build., 34: 661-665. DOI: 10.1016/S0378-7788(02)00017-8

Investopedia US, 2013. Correlation coefficient.

Jendritzky, G., 1991. Selected questions of topical interest in human bioclimatology. Int. J. Biometeorol., 35: 139-50. DOI: 10.1007/BF01049060

Kantor, N. and J. Unger, 2010. Benefits and opportunities of adopting GIS in thermal comfort studies in resting places: An urban park as an example. Landscape Urban Plann., 68: 36-46. DOI: 10.1016/j.landurbplan.2010.07.008

Kenny, N.A., J.S. Warland, R.D. Brown and T.G. Gillespie, 2009. Part A: Assessing the performance of the COMFA outdoor thermal comfort model on subjects performing physical activity. Int. J. Biometeorol., 53: 415-428.

DOI: $10.1007 / \mathrm{s} 00484-009-0226-3$

Mayer, H. and P. Hoppe, 1987. Thermal comfort of man in different urban environments. Theor. Appl. Clim., 38: 43-49. DOI: 10.1007/BF00866252

MMD, 2013. Monthly weather bulletin. Malaysian Meteorological Department.
Monteiro, L.M. and M.P. Alucci, 2006. Calibration of outdoor thermal comfort models. Proceedings of the 23rd Conference on Passive and Low Energy Architecture, Sept. 6-8, Geneva, Switzerland.

Monteiro, L.M. and M.P. Alucci, 2009. The impact of vegetation on outdoor thermal comfort in urban spaces. Proceedings of the 7 th International Conference on Urban Climate, Jun. 29-Jul. 3, Yokohama, Japan.

Nasir, R.A., S.S. Ahmad and A.Z. Ahmed, 2012. Outdoor thermal comfort in a Malaysian urban park. Proceedings of the 8th International Conference on Urban Climates, Aug. 6-10, UCD, Dublin Ireland.

NE, 2010. Green belts: A greener future. A report by Natural England and the Campaign to Protect Rural England. London, UK.

Nikolopoulou, M. and K. Steemers, 2003. Thermal comfort and psychological adaptation as a guide for designing urban spaces. Energy Build., 35: 95-101. DOI: $10.1016 / \mathrm{S} 0378-7788(02) 00084-1$

Nikolopoulou, M., S. Lykoudis and M. Kikira, 2004. Thermal comfort in outdoor spaces: Field studies in Greece. Centre for Renewable Energy Sources (C.R.E.S.).

Oliveira, S. and H. Andrade, 2007. An initial assessment of the bioclimatic comfort in an outdoor public space in Lisbon. Int. J. Biometeorol., 52: 69-84. DOI: $10.1007 / \mathrm{s} 00484-007-0100-0$

PGM, 2012. REDHA eyes RM10b annually for energyefficient building. Property Guru Malaysia.

Zambrano, L., C. Malafaia and L.E. Bastos, 2006. Thermal comfort evaluation in outdoor space of tropical humid climate. Proceedings of the 23rd Conference on Passive and Low Energy Architecture, Sept. 6-8, Geneva, Switzerland. 